\title{
Effect of repeated colloidal bismuth subcitrate treatment on the response of the rat gastric mucosa to the presence of luminal ethanol
}

\author{
S M Hinsull, D Bellamy
}

\begin{abstract}
The purpose of this study was to determine the effects of repeated colloidal bismuth subcitrate administration on the cellular populations of the fundic region of the rat stomach and to investigate the effect of such treatment, after initial ethanol damage, on the gastric response to a second challenge by ethanol. The administration of $240 \mathrm{mg}$ of colloidal bismuth subcitrate per kilogram body weight, at $\mathbf{1 2}$ hour intervals, for $\mathbf{1 4}$ days, resulted in an increase in the density of the mucosal epithelial cells, but a decreased rate of epithelial cell division in the neck region. Comparison with placebo treated animals showed that the repeated administration of colloidal bismuth subcitrate after an initial ethanol challenge, decreased the degree of damage induced by a second ethanol challenge, enhanced the rate of tissue repair and prevented the establishment of persistent erosions.
\end{abstract}

Colloidal bismuth subcitrate (CBS) is an established protective and therapeutic agent for the treatment of a number of gastrointestinal disorders. ${ }^{12}$ The protective and remedial actions of CBS are the results of a number of its properties. Colloidal bismuth subcitrate has been shown to bind to and stabilise the mucus, thus increasing the resistance to the back diffusion of hydrogen ions. ${ }^{3}$ Colloidal bismuth subcitrate also has the ability to preferentially bind to the areas of gastric damage, ${ }^{4}$ stimulate mucus secretion, ${ }^{5}$ inhibit pepsin secretion, ${ }^{6}$ actively bind bile salts ${ }^{7}$ and inhibit pyloric Helicobacter, ${ }^{8}$ which has been implicated as the causative agent in gastritis. ' The mechanisms of action of CBS, however, have yet to be fully elaborated, but it is becoming increasingly obvious that a number of biochemical events are involved in this defensive action, with the increased production of prostaglandins $\mathrm{s}^{10-12}$ and glycoprotein complexes ${ }^{13}$ contributing to the protective effect.

The potential of CBS as a protective agent has been demonstrated by experimental work which has shown that short term pretreatment with CBS can prevent gastric damage by ulcerogenic agents. ${ }^{10-12}$ There is little information, however, on the protective action of CBS after repeated treatment, particularly in relation to the recurrence of gastric damage in previously injured tissue; although it has been shown that patients treated with CBS have lower rates of relapse compared with patients given $\mathrm{H}_{2}$ blockers. ${ }^{14}$ is The aim of these experiments was to investigate the effects of prolonged CBS treatment after ethanol damage and its ability to protect the stomach against a second ethanol challenge.

\section{Methods}

ANIMAL TREATMENT

Forty, nine week old, male rats, of a WAB substrain, were used throughout the following experiments. The animals were routinely maintained on a standard pelleted diet and tap water ad libitum. The animals were weight matched and allocated to one of four experimental groups, each containing 10 animals, one week before the start of the experiment. The four groups consisted of animals treated with: (i) ethanol alone, (ii) $\mathrm{CBS}$ alone, (iii) ethanol+CBS, (iv) distilled water.

Food, but not water, was withheld from all of the animals for 24 hours before the experiment began. On day 1 of the experiment, the ethanol alone and ethanol+CBS groups were given $4 \mu \mathrm{l}$ of $100 \%$ ethanol $/ \mathrm{g}$ body weight, by oral intubation. The control and CBS alone groups were given equivalent volumes of distilled water. Drinking water and food were withheld from all groups for one hour after treatment.

The CBS alone and ethanol+CBS groups received $240 \mathrm{mg}$ colloidal bismuth subcitrate/ $\mathrm{kg}$ body weight, by oral intubation two hours after the ethanol administration. Colloidal bismuth subcitrate administration was repeated every 12 hours for the following seven days. The control and ethanol alone groups were given equivalent volumes of distilled water over the same time course.

On day seven of the experiment, a second instillation of absolute ethanol was administered, as previously described, to the fasted, ethanol alone group. Food and water were withheld for a further hour thereafter, and $30 \%$ of the animals in this group were killed at two hours and four hours, and $20 \%$ at 24 hours and seven days after the second dose of ethanol.

The ethanol+CBS group were treated in an identical manner to the ethanol alone animals, but CBS administration was continued at 12 hour intervals. Thirty per cent of the animals from this group were killed at two hours and four hours, and $20 \%$ at 24 hours and seven days after the second ethanol instillation.

The CBS alone group were given $4 \mu$ distilled water/g body weight on day seven of the experiment. Half of the animals in this group were killed on day 7, one hour after the final CBS dose. The remaining animals were maintained on the 12 hour CBS regime for a further seven days and killed after a total of 14 days of CBS treatment. 
Distilled water was used as the placebo to CBS and ethanol in the control animals. All of the animals were given $2 \mathrm{mg}$ colchicine/ $\mathrm{kg}$ body weight, by intraperitoneal injection, two hours before death in order to arrest dividing cells at metaphase.

\section{HISTOLOGY}

The animals were killed by cervical dislocation. The abdominal cavity was opened immediately and ligatures applied to the oesophageal and duodenal junctions of the stomach. $0.5 \mathrm{ml}$ fixative (consisting of nine parts buffered neutral formalin: one part acetone) at $4^{\circ} \mathrm{C}$, was injected into the gastric lumen. The ligatured stomach was removed entire and placed into the same fixative for a further 30 minutes. The stomach was opened along the greater curvature and placed in fresh fixative at room temperature for a further 17 hours. Tissue samples were taken from comparable regions of each stomach. Two $8 \mathrm{~mm}$ horizontal strips of tissue were removed from the upper surface of the fundic region of each stomach, beginning $3 \mathrm{~mm}$ below the squamous stomach and midway between the greater and lesser curvature. The tissue samples were placed into two changes of acetone for $\mathbf{3 0}$ minutes and embedded in a water soluble methacrylate medium. Thirty sections were cut from each tissue sample and every third section was taken for examination, giving a total of 20 mounted sections from each experimental animal. Sections were cut at $2 \mu$ and sections from each tissue sample were stained according to the following techniques: (1) Gordon and Sweet's method for reticulin staining, ${ }^{16}$ lightly counterstained with Mayer's haemalum. (2) Nuclear staining using a double staining method which consisted of a prestaining with celestine blue in order to intensify the action of Mayer's haemalum as a nuclear stain. (3) Brucine iodine for bismuth. Modified Castell's reagent ${ }^{17}$ was used, in conjunction with Mayer's haemalum counterstain, in order to locate bismuth deposits in the tissue.
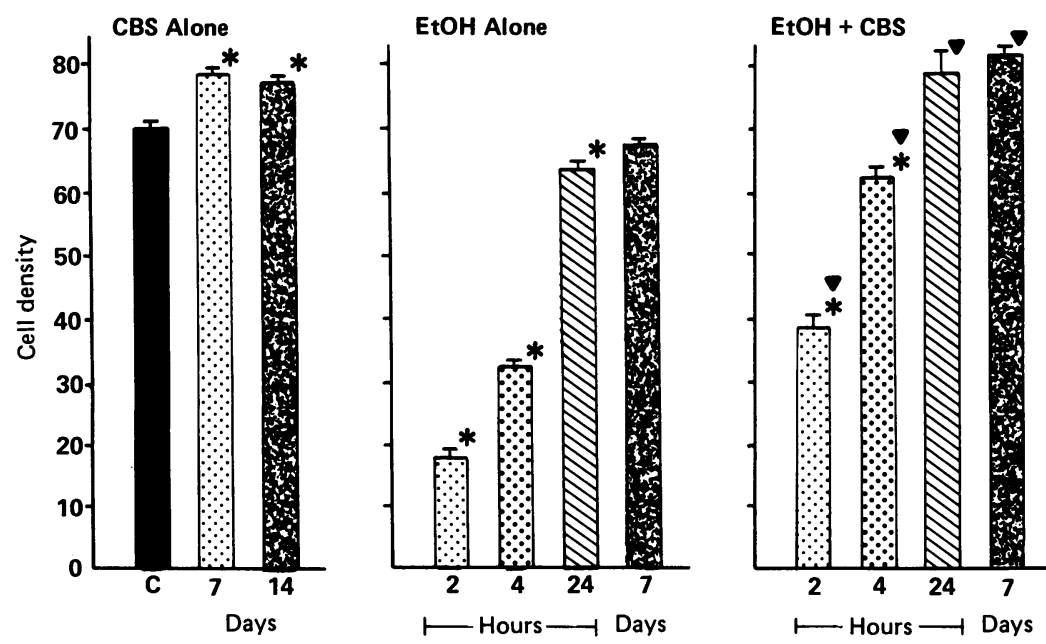

Figure 1: Epithelial cell densities in the gastric mucosa. Control $\mathrm{CBS}$ treatment alone $\mathrm{D}$ for

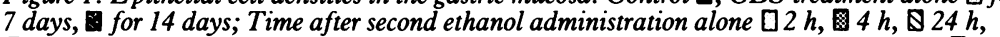
7 day; Time after second ethanol administration plus continuous treatment with CBS $\square 2 \mathrm{~h}$,

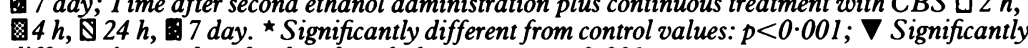
different from values for the ethanol alone group: $p<0.001$
MORPHOMETRY

All of the histological preparation was carried out by one individual to ensure uniformity of procedure. The sections were mounted onto coded slides so that the two authors performing the various morphometric analyses were unaware of the treatment to which the tissue had been subjected. Reticulin stained tissue sections were used to check the vertical orientation of the tissue. Only tissue cut in a vertical plane was used for morphometry and cell counts. Mucosal epithelial cell depths were determined using nuclear stained sections. The total depth of the mucosal cell population was measured from the top of the mucosal surface to their furthest limits in the neck region.

Cell counts were carried out using nuclear stained material mounted on coded slides. Each microscope area (170 $\mu$ diam) covered three gastric pits. The total number of epithelial cells in the surface epithelium were counted in each microscope area. The number of parietal, epithelial and dividing cells, per microscope area, were also determined in the neck region. Two hundred microscope areas were counted for each region in each experimental group. A two sample $t$-test was used to test the significance of the differences between the mean values of the cell types and a $\chi^{2}$ analysis was used to test for significant shifts in cell distribution patterns. Each area was also categorised according to the degree of damage. Five categories were recognised for this purpose: (1) Intact with no microscopic evidence of damage. (D1) Superficial damage to the surface mucosal epithelial cells. (D2) Destruction of all the surface mucosal epithelial cells. (D3) Erosion into the superficial neck region. (D4) Erosion into the neck region. (D5) Erosion into the fundic gland region.

\section{Results}

The administration of $240 \mathrm{mg}$ of CBS/ $\mathrm{kg}$ body weight had no apparent ill effects on the growth and general welfare of the animals. The use of brucine iodide, for the detection of bismuth, on histological sections showed discrete deposits of bismuth over the mucosal epithelial surface at two and four hours after CBS administration, whereas control sections from animals not given CBS showed no indication of such deposits when stained with brucine iodide. By six hours after CBS administration, bismuth could not be detected in the tissue sections using this technique.

Microscopic examination of the gastric fundic region indicated that CBS repeated treatment was associated with an increase in the number and distribution of the mucosal epithelial cells. The total number of epithelial cells in each microscope area, which covered three gastric pits, was scored. The mean number of mucosal epithelial cell in the animals treated with CBS for seven or 14 days were both statistically significantly $(\mathrm{p}<0.001)$ higher than control values (Fig 1). The increase in epithelial cell numbers after CBS treatment was further exemplified in the cell density distribution patterns. Each microscope area counted was categorised according to cell density - that is, the number of cells 

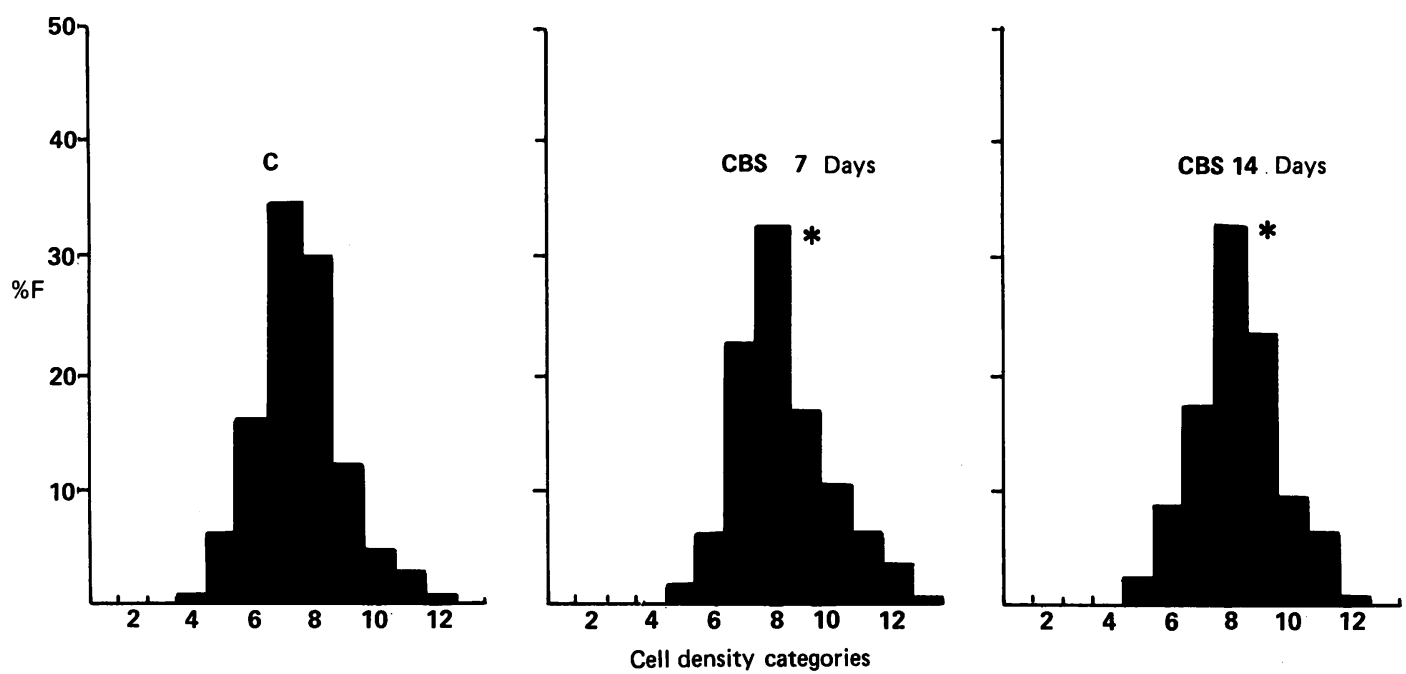

Figure 2: Frequency distribution of mucosal epithelial cell densities. $C$-Control treated with distilled water placebo. CBS $7 D$ - Treatment with $240 \mathrm{mg} C B S / \mathrm{kg}$ body weight every $12 \mathrm{~h}$ for 7 days. CBS $14 \mathrm{D}-$ Treatment with $240 \mathrm{mg} C B S / \mathrm{kg}$ body weight every $12 \mathrm{~h}$ for 14 days. ${ }^{\star}$ Significantly different from the control distribution pattern: $p<0 \cdot 001$.
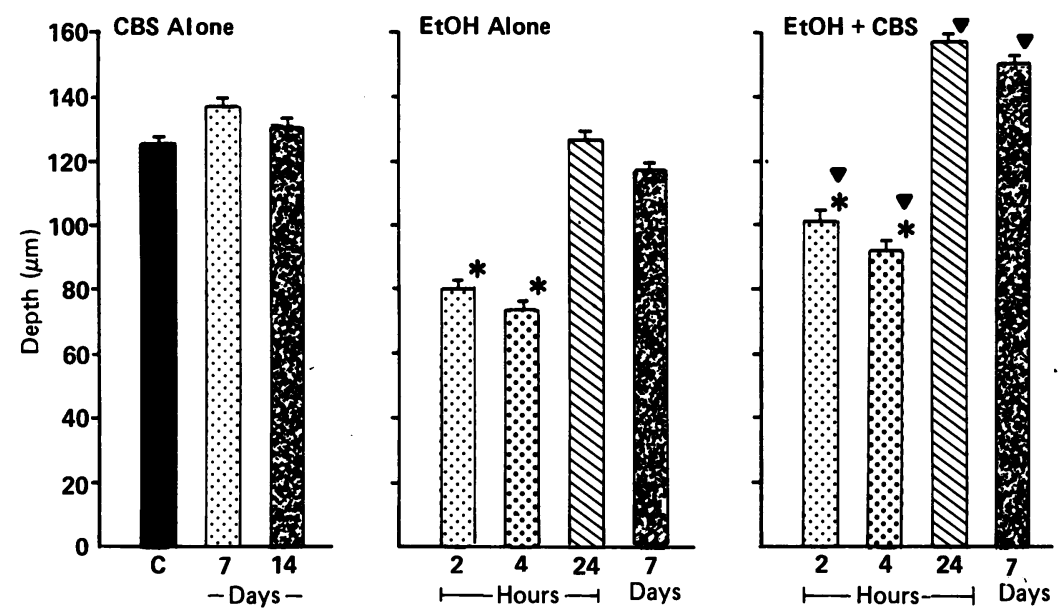

Figure 3: Epithelial mucosal depth measurements. Control ; CBS treatment alone $\mathrm{D}$ for 7 days, for 14 days; Time after second ethanol administration alone $12 h$, 囷 $4 h$, $24 h$

7 day; Time after second ethanol administration plus continuous treatment with CBS $2 \mathrm{~h}$, $4 \mathrm{~h}, \mathrm{~B} 24 \mathrm{~h}, 7$ day. ${ }^{*}$ Significantly different from control values: $p<0 \cdot 001 ; \boldsymbol{\nabla}$ Significantly different from values for the ethanol alone group: $p<0.001$.

in the area. Category 1 represented the lowest density categories with between 0 and 10 cells in the area. Category 13 represented the highest density categories with 121-130 cells in each area. Figure 2 shows the frequency distribution of the areas counted in each of these categories. In tissue from the control animals the majority of the areas counted fell into category 7 (61-70 cells/ area), whereas a significant shift $(p<0.001)$ to the higher density categories was observed in both of the groups treated with CBS (Fig 2). With CBS treatment, the peak distribution occurred in category 8 (71-80 cells/area), with fewer areas falling into the lower density categories compared with the controls. In addition to the increase in mucosal epithelial cell density with CBS administration, it was also found that the depth of the epithelial cell region increased when the animals were given CBS (Fig 3).

Colloidal bismuth subcitrate treatment also had a significant effect on the cellular popula-

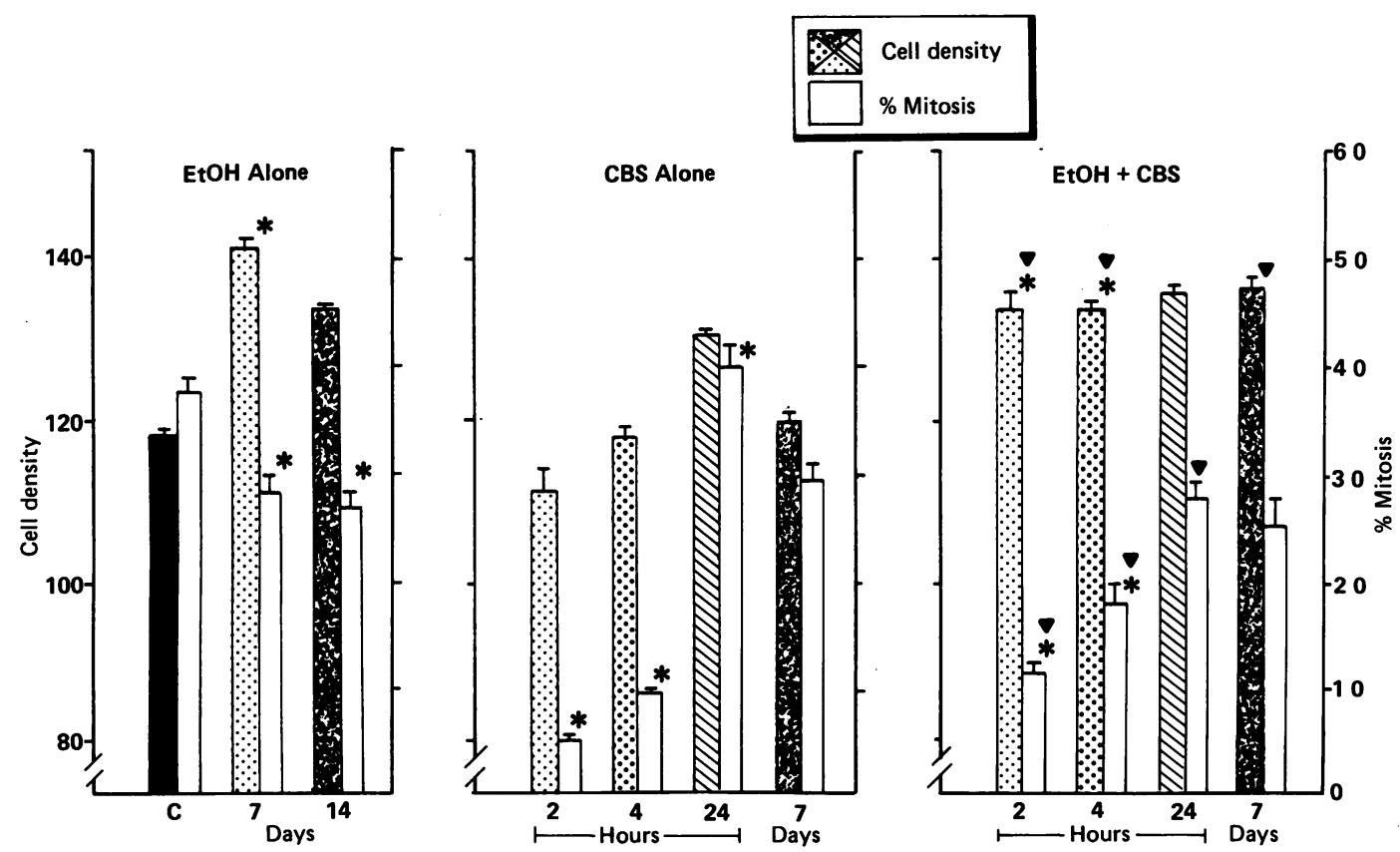

Figure 4: Total cell densities and mitotic rates in the neck region. Control 1 ; $C B S$ treatment alone $[$ for 7 days, for 14 days, Time after second ethanol administration alone $72 \mathrm{~h}, \mathrm{O}, \mathrm{h}, \mathrm{Q} 24 \mathrm{~h}, \mathrm{i}$ day; Time after second ethanol administration plus continuous treatment with $C B S \square 2 h, 04 h, \mathbb{2} 24 h, 17$ day. Corresponding mitotic rates indicated by accompanying

histograms; * Significantly different from control values: $p<0.001 ; \nabla$ Significantly different from values for the ethanol alone group: $p<0 \cdot 001$. 
a Neck epithelial cell density
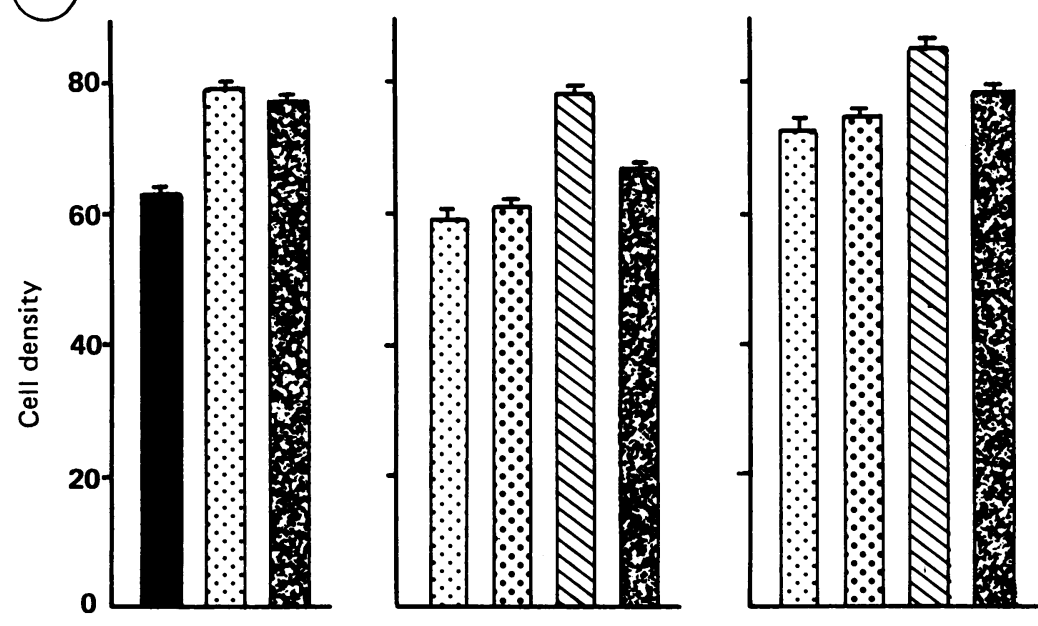

(b) Neck parietal cell density

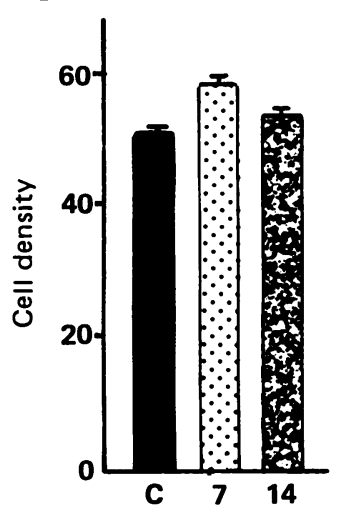

CBS Alone

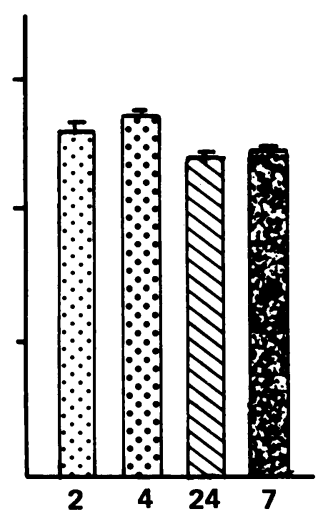

EtOH Alone
$\mathrm{EtOH}+\mathrm{CBS}$

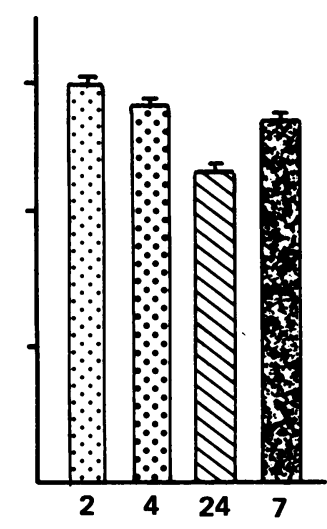

Figure 5: A-Density of epithelial cells in the neck region. B-Density of parietal cells in the neck region. Control 1 ; $C B S$ treatment alone $\square$ for 7 days, 14 for 14 day; Time after second ethanol administration alone $\square 2 h, \mathbb{Q} 4 \mathrm{~h}, \mathbb{Q} 24 \mathrm{~h}$, 7 day; Time after second ethanol administration plus continuous treatment with $C B S \square 2 h$, $4 h, \mathbb{Q} 24 h$, 7 day.

$\star$ Significantly different from control values: $p<0.001 ; \nabla$ Significantly different from values for the ethanol alone group: $p<0.001$. only $10 \%$ of the areas were classified as severely damaged (Fig 7).

The degree of damage in the animals given ethanol alone was reflected in a significant $(\mathrm{p}<0.001)$ depletion of mucosal epithelial cells (Fig 1). Figure 8a shows that ethanol alone resulted in a significant shift $(p<0.001)$ in the distribution of cell densities to the lower categories compared with the controls. At two hours after ethanol administration more than $50 \%$ of the areas contained fewer than 10 epithelial cells, indicating almost complete destruction of the surface mucosal epithelial cells in these areas (Fig 8a). Only $5 \%$ of the areas attained cell densities falling into categories 7 and 8, where the peak in cell densities were found in the tissue from control and CBS alone groups. Although ethanol damage was observed in the CBS treated animals, it was far less severe than that found with ethanol administration alone. Thus the distribution of cell densities was significantly $(\mathrm{p}<0.001)$ higher in the ethanol+CBS group than in the ethanol alone group. Only $26 \%$ of the ethanol+CBS areas fell into category 1 and some areas were distributed into the higher cell density categories (Fig 9a). Correspondingly, mucosal depth measurements were $36 \%$ lower than control values after ethanol treatment alone $(\mathrm{p}<0.001)$, whereas in the ethanol+CBS group the mean mucosal depth was $19 \%$ lower than control values but was significantly $(p<0.001)$ higher in the ethanol alone group (Fig 3).

Ethanol instillation resulted in a significant $(p<0.001)$ decrease in the number of mitotic figures recorded in the neck regions of both the placebo and CBS treated animals (Fig 4). Some depletion of the total cellular population of the neck region was found in both the ethanol alone and ethanol+CBS groups (Fig 4). This was mainly the result of a significant decline $(p<0.001)$ in epithelial cell numbers, with no significant change in the number of parietal cells (Fig 5).

At four hours after ethanol administration there were signs of initial repair to the damaged areas. The majority of the damaged areas were covered by a single layer of epithelial cells (Figure 10). In some cases the underlying tissue still showed signs of lesions deep into the glandular region. Despite this initial restitution of the epithelial layer, no significant changes in the mucosal depth measurements were observed in either group between two and four hours after the ethanol administration (Fig 3). There was a significant $(p<0.001)$ increase, however, in the mean density of the mucosal epithelial cells (Fig 1). The re-epithelialisation of the mucosal surface resulted in a dramatic fall in the incidence of areas containing less than 10 cells per area $(p<0.001)$, with the majority of areas falling into categories $2-4$ in the ethanol alone group (Fig 8). In the ethanol+CBS group, recovery was significantly $(p<0.001)$ further advanced than in the ethanol alone group, with the majority of areas occurring in categories 7-9 (Fig 9). When compared with values at two hours, the restitution of the epithelial layer at four hours after ethanol was correlated with a significant increase $(p<0.001)$ in mitotic rate in both the ethanol alone and ethanol $+\mathrm{CBS}$ groups. The indication of damage and were classified confined to the mucosal epithelial cells, but of the areas had severe haemorrhagic lesions extending into the neck region and beyond (Fig $7)$. The damage was far less severe $(p<0.001)$ in the animals treated with CBS. In this group, $32 \%$ of the areas remained undamaged and 

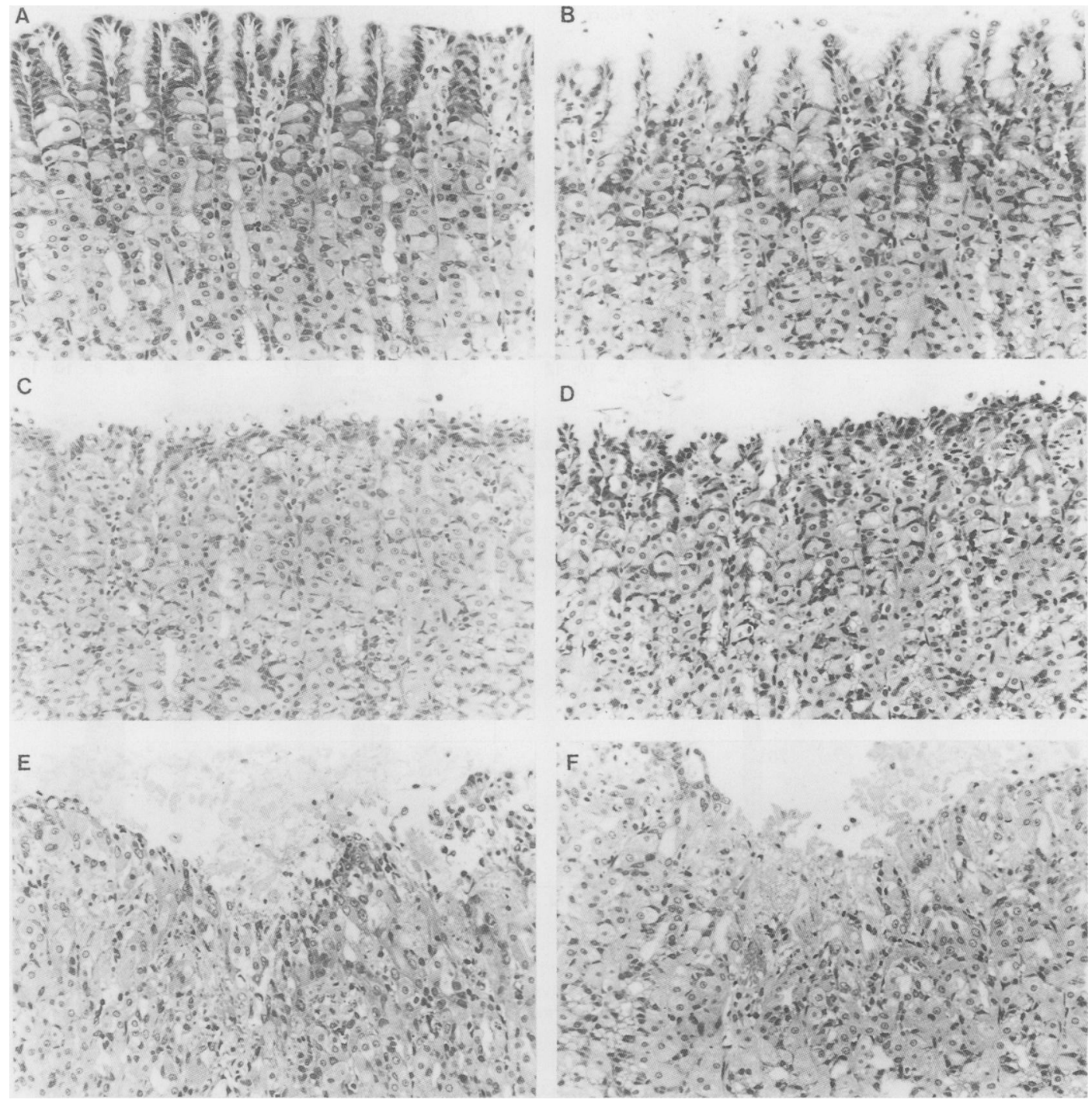

Figure 6: Categories of gastric damage identified at two hours after ethanol administration. A-1, Intake area showing no signs of microscopic damage; $B-D 1$ superficial damage to surface epithelial cells; $C-D 2$, total destruction of the surface epithelial cells; $D-D 3$, erosion into the superficial neck region; $E-D 4$, erosion deep into the neck region; $F-D 5$, erosion into the fundic gland region.

mitotic rate in the ethanol alone group, however, was still $74 \%$ lower than control values $(\mathrm{p}<0.001)$, whereas in the ethanol+CBS group the rate was $36 \%$ below that of the CBS alone group ( $\mathrm{p}<0.001$, Fig 4$)$. The numbers of resting epithelial cells and parietal cells in the ethanol

EtOH Alone

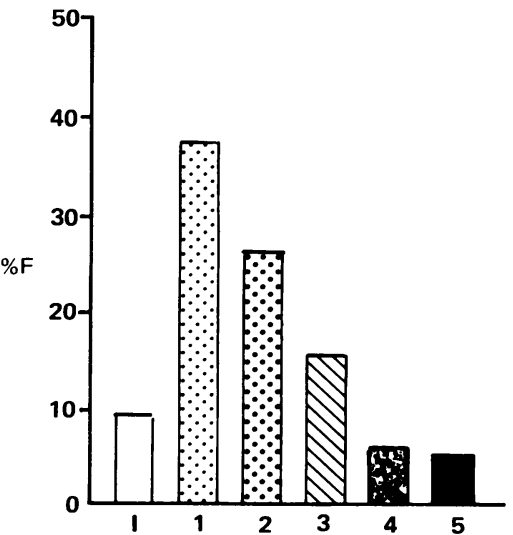

$\mathrm{EtOH}+\mathrm{CBS}$

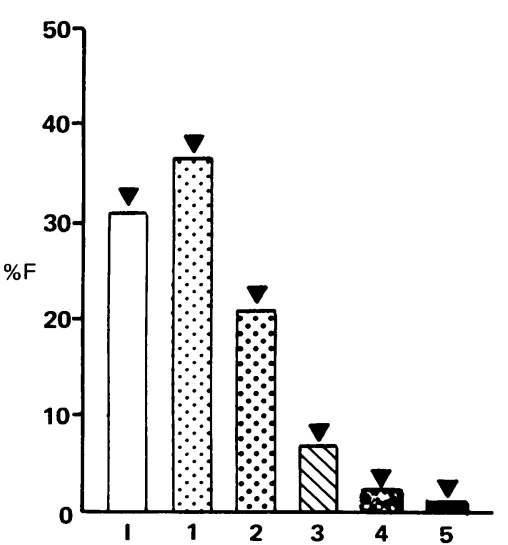

Figure 7: Microscopic assessment of damage at two hours after ethanol administration.

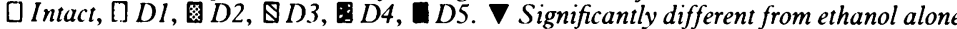
group: $p<0 \cdot 001$. alone and the ethanol+CBS groups were not significantly different from their respective control values.

At 24 hours after the second ethanol dose, recovery was at an advanced stage. Mucosal depths had attained levels which were comparable with control values in both the ethanol alone and the ethanol+CBS groups (Fig 3). Similarly, the number and density distribution of these cells showed a further shift into the control range (Figs 8c and 9c). The mucosal epithelial cell numbers in the ethanol+CBS groups were not significantly different from those found in the animals treated with CBS alone, but in the animals treated with ethanol alone the epithelial cells numbers were still significantly lower than control values $(p<0.001)$. Accordingly, the rate of cell division in the ethanol alone group was significantly higher than control values at this stage $(p<0.001)$. In contrast, the rate of mitosis in the ethanol+CBS group was not significantly different from that of animals treated with CBS alone.

At seven days after the second ethanol administration restitution of the gastric mucosa was virtually complete (Figs 1 and $8 d$ ). The cellular 

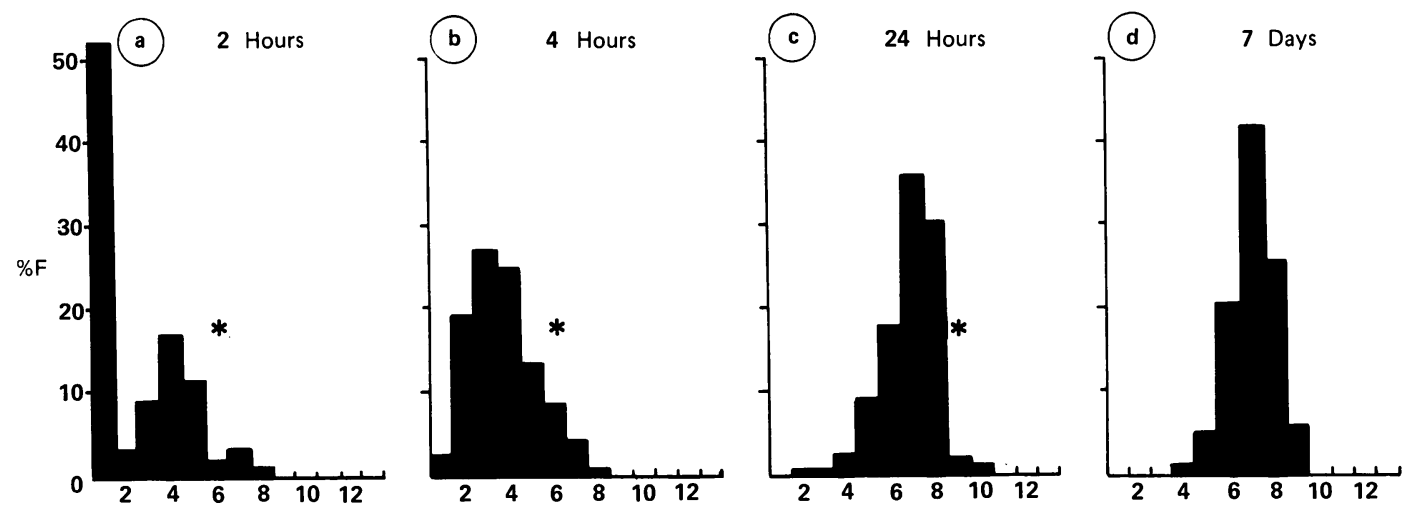

Cell density categories

Figure 8: Frequency distribution of mucosal epithelial cells in animals given ethanol alone at: $A-2 h, B-4 h, C-24 h$ and $D-7$ days after ethanol administration. ${ }^{\star}$ Significantly different from control values: $p<0 \cdot 001 ; \nabla$ Significantly different from values for the ethanol alone group: $p<0 \cdot 001$.
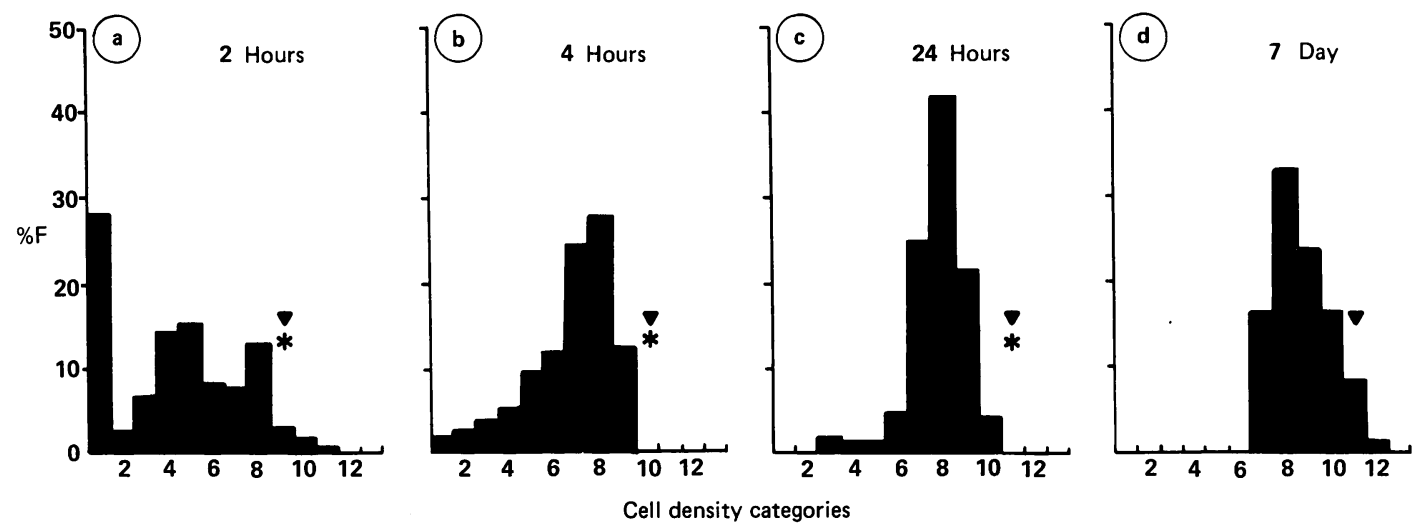

Figure 9: Frequency distribution of mucosal epithelial cell densities in animals given ethanol and treated with $C B S$ at $A-2 h$, $B-4 h, C-24 h$ and $D-7$ days after ethanol administration. ${ }^{\star}$ Significantly different from control values: $p<0 \cdot 001 ; \nabla$ Significantly different from values for the ethanol alone group: $p<0 \cdot 001$.

populations of the mucosal and neck regions from the ethanol alone and ethanol+CBS treated groups were comparable with the control and CBS alone groups respectively (Figs 1, 3, 4, 5). In the ethanol alone group, however, there were a few areas where erosions persisted (Fig 11). In the ethanol+CBS group there was no indication of erosions but there were signs of bifurcations in the lines of epithelial cells at the tops of the pits which is frequently observed after gastric injury (Fig 12).

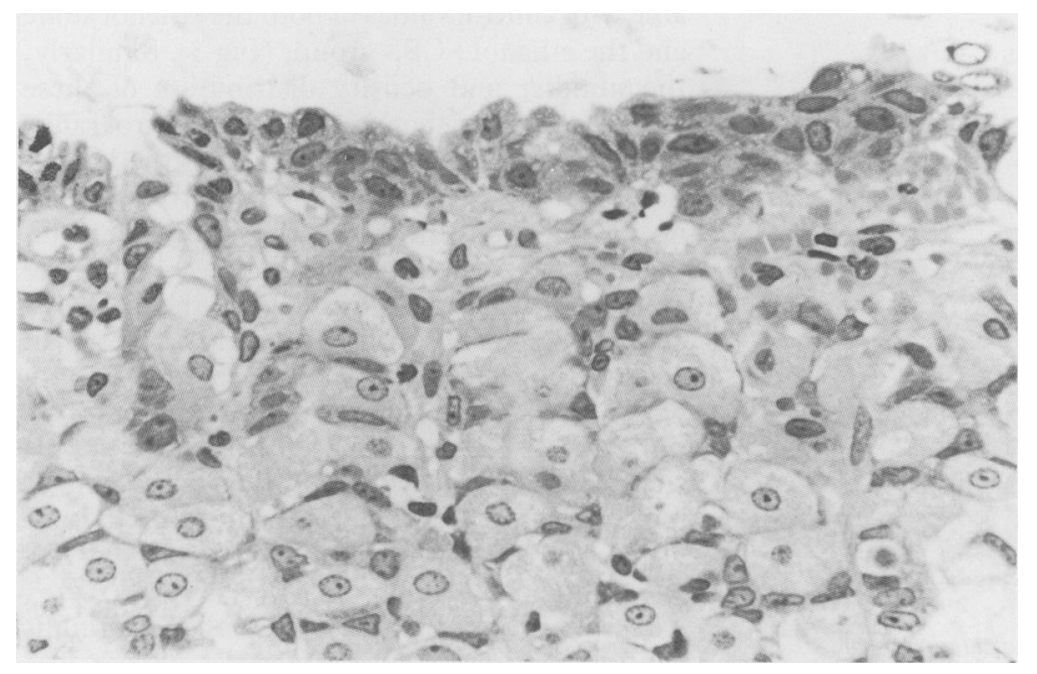

Figure 10: Epithelial cell cover at four hours after ethanol administration.

\section{Discussion}

In a clinical situation it is usual to administer CBS in the fasting state, but the experimental regime used in this study, consisting of repeatedly administering CBS at 12 hourly intervals, precluded the use of continuously fasted animals. The use of brucine iodide staining demonstrated the presence of bismuth at the luminal surface of the stomach at two and four hours after CBS administration, however, suggesting that $\mathrm{CBS}$ was bound to the mucus layer in the present experimental regime. The dose of CBS used in these experiments was higher than the standard therapeutic doses but was comparable with the levels given to experimental animals by other workers and, in particular, is known to increase gastric prostaglandin generation. ${ }^{10-12}$

The present study shows that repeated CBS treatment results in an increase in the density of the mucosal epithelial cells, as well as an increase in mucosal thickness. It is possible that these effects of CBS on the mucosal epithelial cells were the result of factors such as contraction of the gastric smooth muscle. Contraction of the smooth muscle, however, would result in an increase in the density of all of the mucosal cell types. As no significant change was found in the parietal cell numbers, and the proliferative cell numbers decreased, the suggested role of smooth muscle in the effects of CBS on the mucosal epithelial cells appears improbable. 


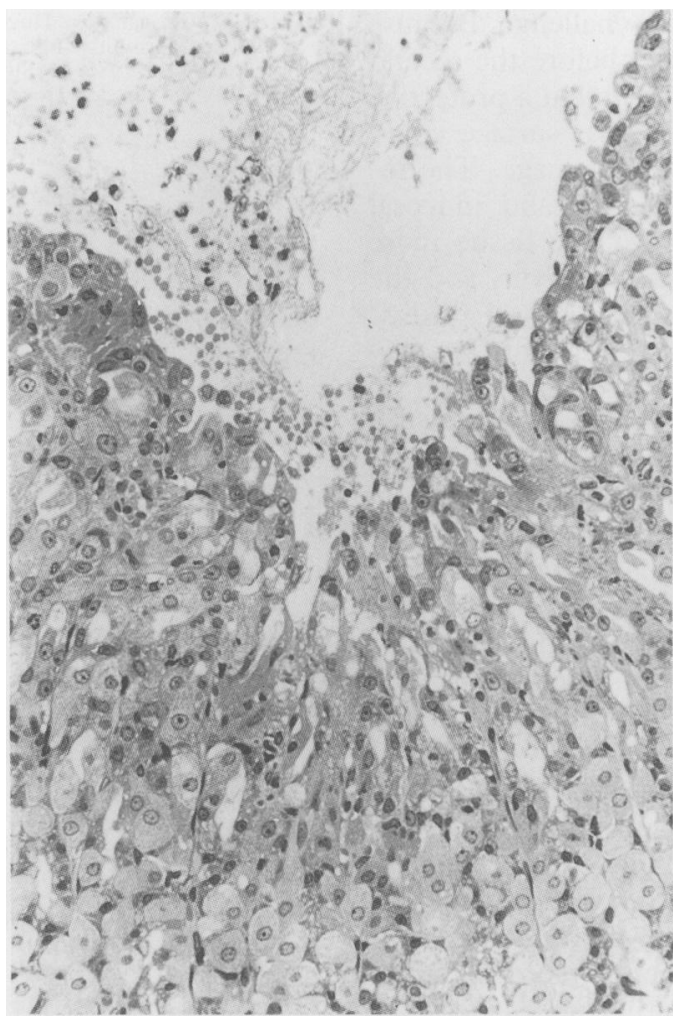

Figure 11: Persistent erosion at seven days after ethanol administration alone.

The action of CBS on the mucosal epithelial cells was associated with a decline in the rate of cellular proliferation in the neck region, suggesting that the increase in the epithelial cell population was not the result of an increase in the rate of proliferation of the stem cell population. Previous reports have shown that a single dose of CBS forms a coating which effectively protects the stomach against damage. ${ }^{18} 18$ The mechanism which mediates this protective action of CBS has not been fully elucidated, but it has been shown that CBS precipitates on the mucosal surface to form a diffusion barrier to hydrogen ions, as well as inactivating pepsin, stimulating mucus secretion, binding bile salts and inhibiting Helicobacter. ${ }^{127819-21}$ In addition, there is an increasing

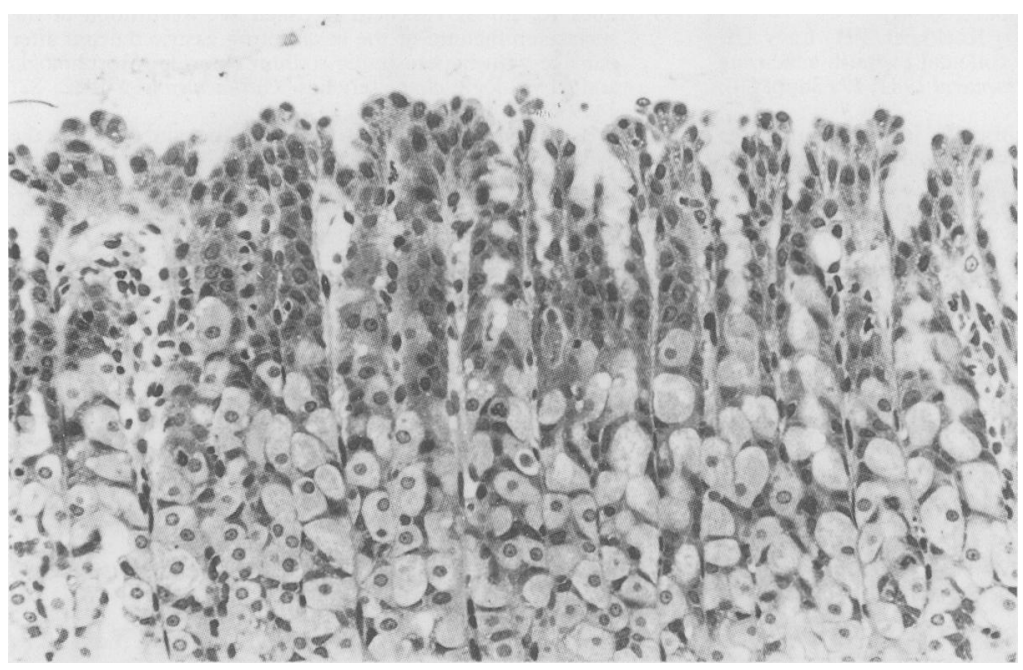

Figure 12: Bifurcation of mucosal surface pit structure at seven days after ethanol administration in animals treated with ethanol plus $C B S$. amount of evidence to suggest that the actions of CBS may be partially mediated via the action of secondary agents such as prostaglandins and epidermal growth factor. Prostaglandins are known to be secreted by the gastric mucosa and it has been suggested that they play an important role in maintaining the integrity of this tissue. ${ }^{22-25}$ Colloidal bismuth subcitrate has been shown to stimulate the production of prostaglandins and it has been suggested that the efficacy of CBS as a gastroprotective agent may be, in part, a result of increased prostaglandin production. ${ }^{10-1222}$ The processes which may be involved in such a system have yet to be clarified but experiments on longterm treatment with an analogue of $\mathrm{PGE}_{2}$ resulted in a thickening of the mucosa which, as in the present experiments, was not associated with an increased rate of cellular proliferation. ${ }^{26}$

It seems improbable, however, that prostaglandins are the sole secondary agents involved in mediating this action of CBS as CBS also protects against aspirin induced gastric injury, where PG cyclooxygenase is inhibited. ${ }^{10} \mathrm{~A}$ more precise assessment of the role of prostaglandins in the present system would be gained by the administration of repeated doses of CBS together with a cyclooxygenase inhibitor. In addition, when gastroprotective doses of $\mathrm{PGE}_{2}$ have been administered to both animals ${ }^{10}$ and humans, ${ }^{27}$ they have been unsuccessful in promoting ulcer healing. In contrast, CBS has been shown to have both gastroprotective and ulcer healing properties. "15 21 As there is substantial evidence that epidermal growth factor is a potent growth promoter and acts as a gastroprotective as well as an ulcer healing agent, ${ }^{28-31}$ it has been suggested that epidermal growth factor may be involved in mediating the action of CBS. Recent work has shown that the cytoprotective actions of CBS are unimpaired by sialoadenectomy, but that removal of the salivary glands reduced the ulcer healing capacity of CBS..$^{32}$ The same series of experiments also showed that epidermal growth factor is bound to CBS in a pH dependent manner, such that epidermal growth factor accumulates at sites of gastric damage. ${ }^{32}$ This evidence suggests that epidermal growth factor may be involved in the ulcer healing actions rather than the gastroprotective actions of CBS. In the present experiments the increased mucosal thickness and density of epithelial cells observed after CBS administration was not associated with an increase in the mitotic rate of the stem cell population. If epidermal growth factor, a potent mitogen, is involved in this action of CBS, an increased mitotic rate would have been anticipated. A role for epidermal growth factor in the repair of alcohol induced gastric damage, however, cannot be excluded.

The restitution of the gastric mucosa after damage induced by a single application of ethanol, with and without the use of protective agents, has been described by a number of workers. ${ }^{33-35}$ In the present experiments the stomach was challenged with ethanol for a second time seven days after ethanol was first administered. Colloidal bismuth subcitrate treatment during the intervening seven days significantly limited the degree of damage in- 
duced by the second ethanol challenge. Because the CBS was given 12 hours before the second ethanol dose, it seems unlikely that a protective coating of CBS on the mucosal surface could account for this reduction in damage. The increase in epithelial cell density and mucosal epithelial depth could render the tissue more resistant to ethanol damage, however, and the involvement of other protective mechanisms, such as prostaglandins, ${ }^{22} 2436$ cannot be discounted.

The rate of recovery was faster with CBS treatment, which confirms the reports from other workers, ' and was to be expected when the animals were being treated with CBS at 12 hour intervals. The recovery was also favoured by the initial reduction in damage in the CBS treated rats. In the majority of cases the laminal scaffold, which is essential for rapid tissue reorganisation after damage, ${ }^{33-39}$ remained undamaged in the ethanol+CBS groups.

Although the time course of repair after the second ethanol challenge appeared to be comparable with that reported after initial damage, some of the deep erosions persisted through to the seventh day after the second dose of ethanol alone. In contrast, no erosions were detected in the ethanol +CBS groups at this time, suggesting that CBS did ameliorate the persistence of severe damage. These findings concur with previous reports indicating that CBS is not only successful in promoting the healing of gastroduodenal ulcers but also in reducing ulcer relapse rates. ${ }^{1526+041} \mathrm{~A}$ major implication of the present results is that CBS can cause hypertrophy of the gastric mucosa in experimental animals; an action which may be involved in reducing ulcer relapse rates. As there is little information available on the effect of chronic CBS treatment on the cellular populations of the human stomach, however, the importance of this trophic effect in the human situation is difficult to assess.

This work was supported by a grant from Gist-Brocades, The Netherlands.

1 Tygat GNJ. Colloidal bismuth subcitrate in peptic ulcer - a review. Digestion 1987; 37 (Suppl 2): 31-41.

2 Wieriks J, Hespe W, Jaitly KD, Koekkoek PH, Lavy UI. Pharmacological properties of colloidal bismuth subcitrate (CBS, De-Nol'). Scand F Gastroenterol 1982; 17 (Suppl 80): (CBS

3 Tasman-Jones C, Maher C, Thomsen L, Lee SP, Vanderwee M. Mucosal defences and gastroduodenal disease. Digestion 1987; 37 (Suppl 2): 1-7.

4 Koo J, Hoo J, Lam SK, Wong J, Ong GB. Selective coating of gastric ulcer by tripotassium dicitrato bismuthate in the rat. Gastroenterology 1982; 82: 864-70.

5 Bardhan KD. Prospectives in duodenal ulcer. Welwyn Garden City: Smith, Kline and French, 1981

6 Roberts NV, Taylor WH. The effect of tripotassium dicitrato bismuthate (De-Nol") upon the individual human pepsins. Clin Sci 1982; 63: 65 .

7 Stiel D, Peters TJ. Tripotassium dicitrato bismuthate (De-Nol') binds conjugated bile acids in vitro. A possible
mechanism in gastric ulcer healing. Proc Aust Soc Med Res 1983; 16: 18 .

8 Marshal BJ, McGechie DB, Rogers PA, Glancy RJ. Pyloric Campylobacter infection and gastroduodenal disease. Med $\mathcal{F}$ Aust 1985; 142: 439-44.

9 Goodwin CS, Armstrong JA, Marshall BJ. Campylobacter pyloridis, gastritis and peptic ulceration. $\mathcal{F}$ Clin Pathol 1986

10 Konturek SJ, Radecki T, Piasticki I, Brzozowski T, Drozdowicz D. Gastrocytoprotection by colloidal bismuth subcitrate (De-Nol') and sucralfate. Role of endogenous prostaglandins. Gut 1987; 28: 201-5.
11 Hall DWR, van den Hoven WE. Protective properties of colloidal bismuth subcitrate on gastric mucosa. Scand $\mathcal{F}$ Gastroenterol 1986; 21 (Suppl 122): 11-3.

12 Hall DWR, van den Hoven WE. Gastric mucosa protection and prostaglandin $E_{2}$ generation in rats by colloidal bismuth subcitrate (De-Nol'). Arch Int Pharmacodyn Ther 1987; 286: 308-19.

13 Hollanders D, Morrissey SM, Mehta J. Mucus secretion in gastric ulcer patients treated with tripotassium dicitrate bismuthate (De-Nol'). Br f Clin Pract 1983; 37: 112-4.

14 Bianchi Porro G, Lazzaroni M, Petrillo M, deNicola C. Relapse rates in duodenal ulcer patients formerly treated with bismuth subcitrate or maintained with cimetidine. with bismuth subcit 1984; ii: 698 .

15 Lee FI, Samloff IM, Hardman M. Comparison of tripotassium dicitrato bismuthate tablets with ranitidine in healing and relapse of duodenal ulcers. Lancet 1985; i: 1299-302.

16 Gordon H, Sweets HH. A simple method for silver impregnation. Am F Pathol 1936; 12: 545-52.

17 Wachstein M, Zak FG. Bismuth pigmentation. Its histochemical identification. Am F Pathol 1946; 22: 603-11.

18 Guth PH. Mucosal coating agents and other non-antisecretory agents. Are they cytoprotective? Dig Dis Sci 1987; 32: 647-54.

19 Lee SP. A potential mechanism of action of colloidal bismuth subcitrate, diffusion barrier to hydrochloric acid. Scand $\mathcal{F}$ Gastroenterol 1982; [Suppl 80]: 17-21.

20 Coghill SB. Experimental studies using colloidal bismuth subcitrate: possible modes of action. In: Axon ATR, ed. Pathogenesis and the treatment of peptic ulcer disease. Amsterdam: Excerpta Medica, 1985: 7-12

21 Koelz HR. Protective drugs in the treatment of gastroduodenal ulcer disease. Scand $\mathcal{F}$ Gastroenterol 1986; 21 (Suppl 125): 156-63.

22 Konturek SJ, Radecki T, Piastucki I, Drozdowicz D. Studies on the gastroprotective and ulcer-healing effects of colloidal bismuth subcitrate. Digestion 1987; 37: 8-15.

23 Terano A, Ota S, Mach T, et al. Prostaglandin protects against taurocholate-induced damage to rat gastric mucosal cell culture. Gastroenterology 1987; 92: 669-77.

24 Konturek SJ, Piastucki I, Brzozowski T, et al. Role of locally generated prostaglandins in adaptive gastric cytoprotection. Dig Dis Sci 1982; 27: 967-71.

25 Hawkey CJ, Rampton DS. Prostaglandins in the gastrointestinal mucosa: are they important in its function, disease or treatment? Gastroenterology 1985; 89: 1162-88.

26 Tytgat GNJ, Offerhaus GJA, Van Minnen AJ, Everts V, Hensen-Logmans SC, Samson G. Influence of oral 15(R)-15methyl prostaglandin E2 on human gastric mucosa. Gastroenterology 1986; 90: 1111-20.

27 Wingrower D, Fich A, Goldin E, Eliakim R, Ligumski M, Rachmilewitz D. Cytoprotective doses of arbacet with Rachmilewitz D. Cytoprotective doses of arbacet with minimal antisecretory properties are not effective
denal ulcer healing. Dig Dis $S c i$ 1987; 32: 857-60.

28 Dembenski A, Gregory H, Konturek SJ, Polanski M. Trophic actions of epidermal growth factor on the pancreas and gastroduodenal mucosa of rats. F P hysiol (Lond) 1982; 325: $35-42$

29 Skov Olsen P, Poulsen SS, Kirkegaard P, Nexo E. Role of submandibular saliva and epidermal growth factor in gastric cytoprotection. Gastroenterology 1984;87: 103-8.

30 Skov Olsen P, Poulsen SS, Therkelsen K, Nexo E. Ora administration of synthetic human urogastrone promotes healing of chronic duodenal ulcers in rats. Gastroenterology 1986; $90: 911-7$.

31 Konturek SJ, Dembinski A, Warzecha Z, Brzozowski T Gregory $\mathrm{H}$. Role of epidermal growth factor in healing of chronic gastroduodenal ulcers in rats. Gastroenterology 1988 94: $1300-7$

32 Konturek Sj, Dembinski A, Warzecha Z, Bielanski W, Brzozowski T, Drozdowicz D. Epidermal growth facto (EGF) in the gastroprotective and ulcer healing actions of colloidal bismuth subcitrate (De-Nol') in rats. Gut 1988; 29 894-902.

33 Svanes K, Ito S, Takeuchi K, Silen W. Restitution of the surface epithelium of the in vitro frog gastric mucosa after damage with hyperosmotic sodium chloride. Morphologic and physiologic characteristics. Gastroenterology 1982; 82: and physict

34 Morris GP, Wallace JL. The roles of ethanol and of acid in the production of gastric mucosal erosions in rats. Virchows Arch IV [Cell Pathol] 1981; 38: 23-38

35 Silen W, Ito $S$. Mechanisms for rapid re-epithelialization of the gastric mucosal surface. Ann Rev Physiol 1985; 47: 217-29.

36 Lacy ER, Ito S. Microscopic analysis of ethanol damage to rat gastric mucosa after treatment with prostaglandin. Gastroenterology 1982; 83: 619-25.

37 Vracko R. Basal lamina scaffold - Anatomy and significance for maintenance of orderly tissue structure. Am $\mathcal{F}$ Pathol 1974; 77: 314-39.

38 Ito S, Lacy ER. Morphology of rat gastric damage, defence and restitution in the presence of luminal ethanol. Gastroand restitution in the prese
enterology $1985 ; 88: 250-60$.

39 Black BA, Morris GP, Wallace JL. Effects of acid on the basal lamina of the rat stomach and duodenum. Virchows Arch IV [Cell Pathol] 1985; 50: 109-18.

40 Kang JY, Piper DW. Cimetidine and colloidal bismuth in treatment of chronic duodenal ulcer. Comparison of initial healing and recurrence after healing. Digestion 1982; 23 . 73-8.

41 Hamilton I, O'Connor HI, Wood NJ, Bradburg I, Axon ATR. Healing and recurrence of duodenal ulcers after treatmen with tripotassium dicitrato bismuthate (TDB) tablets or cimetidine. Gut 1986; 27: 106-10. 